\title{
Growing concern about heatstroke this summer in Japan after Fukushima nuclear disaster
}

\author{
Masahide Kondo $\cdot$ Yasushi Honda • \\ Masaji Ono
}

Received: 25 June 2011/ Accepted: 26 June 2011/Published online: 22 July 2011

(C) The Japanese Society for Hygiene 2011

\begin{abstract}
Heat stroke management will be a major challenge following the Fukushima nuclear plant accident that occurred due to the Great East Japan Earthquake. In this article, a number of actions to meet this challenge are proposed.
\end{abstract}

Keywords Climate change - Electricity shortage · Fukushima nuclear disaster - Global warming $\cdot$ Heatstroke

Japan was confronted with an outbreak of heatstroke in the summer of 2010 when the air temperature was more than $1.64^{\circ} \mathrm{C}$ above the normal average summer air temperature. This was the largest deviation in recorded history. The effect of the heat wave was most striking on vulnerable city dwellers, as evidenced by remarkable spikes in the incidence of heatstroke in major Japanese cities (Fig. 1). Preventive measures, such as the proper use of air conditioning or maintenance of adequate oral hydration, had been widely covered in national media, leading to a public awareness of the direct effects of climate change at that time. However, with the publication of the long-range weather forecast last February in which it was reported that this summer would be only as hot as a normal year, people's concern over heatstroke was alleviated to some extent.

\section{Kondo · Y. Honda $(\bowtie)$}

Department of Health Care Policy and Management,

University of Tsukuba, 1-1-1 Tennoudai,

Tsukuba, Ibaraki 305-8577, Japan

e-mail: honda@taiiku.tsukuba.ac.jp

\section{Ono}

Office for Children's Environmental Health Study,

National Institute for Environmental Studies, Tsukuba, Japan

e-mail: onomasaj@nies.go.jp
However, the scenario has changed drastically in the aftermath of the Fukushima nuclear disaster, which followed the Great East Japan Earthquake. The earthquake directly struck Sendai $(175 \mathrm{~km}$ from the epicentre), the second largest city in northern Japan. Healthcare facilities and infrastructure were substantially damaged and will not be fully operational by this summer, possibly exacerbating the fatality rate among future heatstroke sufferers.

There is also a growing concern among public health scientists and practitioners about potential heatstroke cases in other cities around capitol area, including Saitama, Central Tokyo, Kawasaki, and Yokohama. The focus of concern is not radioactive contamination, but on the need to save electricity, since Japan depends heavily on nuclear power plants for its electricity. Due to damage sustained following the earthquake, a number of nuclear power plants, including the Fukushima power plant, and thermal power plants in the northeast area had to be shut down. This resulted in an electricity shortage, and the government enforced a scheduled power cut in the cities mentioned above. Although regular power was restored at the beginning of April following the reduction in electricity demand for air heating and the increase in supply following reparations to the damaged thermal power plants, the demandsupply gap is expected to widen to its maximum during the upcoming summer. Without the electricity supplied by the damaged nuclear power plants, the government may be forced once more to implement a substantial electricity or scheduled power cut. In fact, the Ministry of Economy, Trade and Industry introduced a 15\% electricity cut (compared to the previous summer) policy in May, which became effective not only for industry but also for general households. The guidance urges general households to keep the room air temperature above $28^{\circ} \mathrm{C}$ and to use electric fans instead of air conditioners during the summer 
Fig. 1 Ambulance transports of heatstroke cases during summer 2010 in 12 large cities in Japan. Note: The data on cases have been collected through the network of fire departments in large cities, which started in four cities in 2000 . The data on air temperature were obtained from the Japan Meteorological Agency. The legend on the right is in the descending order of incidence rate in 2010

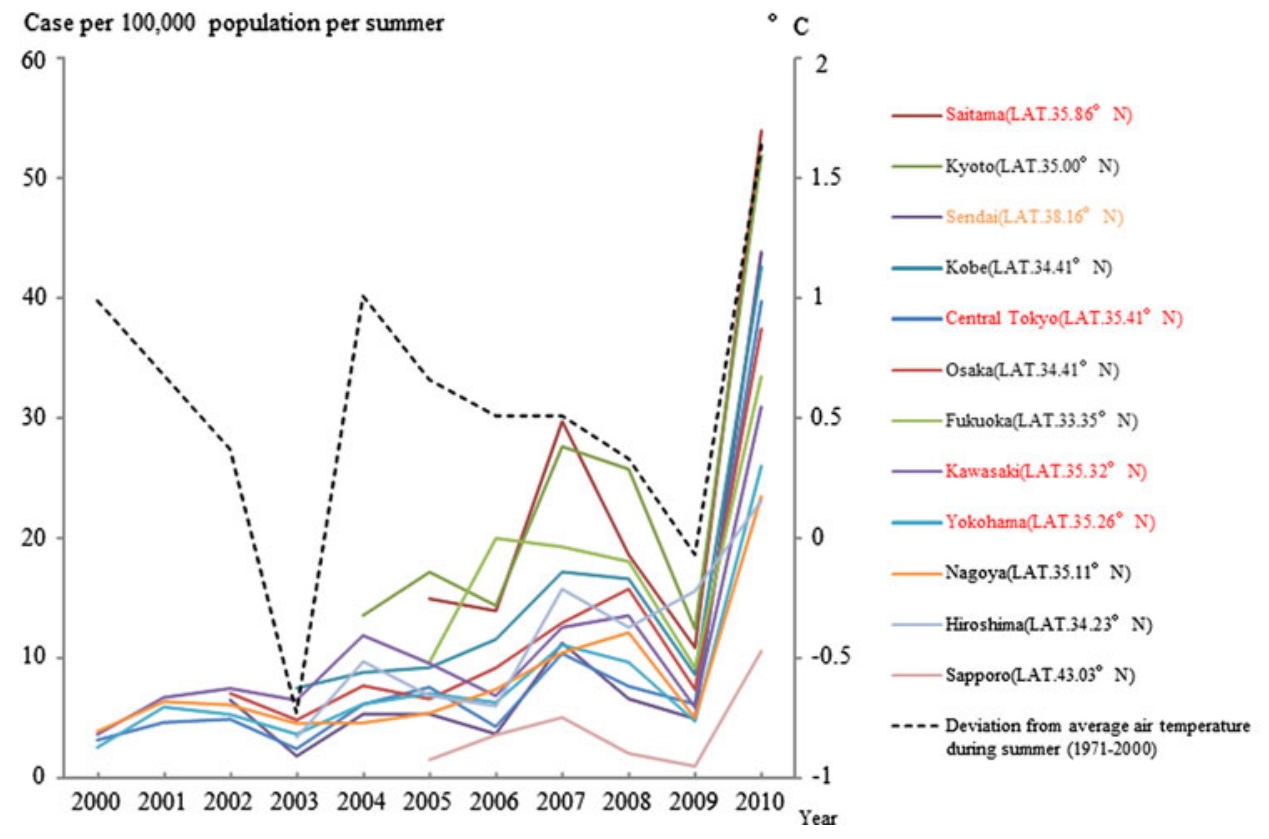

heat, although it also discreetly mentions the risk of heatstroke [1].

In light of vulnerability of city dwellers to heat exposure, insufficient cool air might cause another outbreak of heatstroke. Under the present circumstances, preventing such an outbreak during the summer will be a challenge for public health scientists and practitioners. It is imperative to develop an appropriate risk communication strategy against heatstroke that is in harmony with the short-term policy on the use of electricity in Japan. We consider the following proposals to be important steps in how we should face up to this challenge:

Firstly, we should identify vulnerable populations so that the actions taken are mostly effective. The elderly, those who are 65 years old and over, represent the highest risk and most vulnerable population in this context [2]. Of those reported to suffer from heatstroke last summer, $33.7 \%$ were elderly persons, and $60.6 \%$ of these suffered from heatstroke in their home. Of all heatstroke cases occurring at home, $67.9 \%$ involved an elderly individual. The severity of the heatstroke also tended to be more severe in the elderly than in the younger population.

Secondly, we should develop a system for adaptation to heat waves based both on this information and on the current situation of energy shortage in Japan. Immediate action to be taken is to avoid any power breakdown due to over-usage. Without substantial electricity cuts, the demand will exceed the compromised supply, causing power breakdown. Once a power breakdown occurs, the whole population, including the vulnerable groups, will be exposed to excessive heat and many people will die as a result. In order to avoid such power breakdowns, we should restrict our usage of electricity, while the Japanese government and power companies attempt to increase power supply. At the same time, we should also avoid any overrestriction of electricity usage. In particular, elderly people or those who have cardiorespiratory problems should not refrain from using air-conditioners under high room temperatures. For mid- to long-term management, we recommend that each community center works as a shelter, equipped with air-conditioners and cool water bottles, preferably with an in-house power generator.

There is no doubt that the system for adaptation to heat waves should comply with Japan's low-term low-carbon policy. However, for immediate response to the expected heatwaves, we should not be too concerned about consuming electricity if it is to protect the general public.

Acknowledgments The data collection for Fig. 1 was funded by Environment Research and Technology Development Fund S-4 and S-8 from Ministry of the Environment, Japan. We gratefully acknowledge contributions of Dr. Kayo Ueda and Dr. Masahiro Hashizume for their valuable discussions.

Conflict of interests The authors declare there is no conflict of interests.

\section{References}

1. Agency for Natural Resources and Energy. Katei no setsuden menyu (Household's electricity save menu); 13 May 2011. Tokyo: Ministry of Economy, Trade and Industry. Available at: http:// www.meti.go.jp/setsuden/20110513taisaku/03.pdf. Accessed: 10 June 2011.

2. Ono M. Ueda K. Bulletin report on heatstroke patients 2010. Tsukuba: National Institute for Environmental Studies; February 2011. Available at: http://www.nies.go.jp/health/HeatStroke/spot/ english/index.html. Accessed: 10 June 2011. 